\title{
Principles of capitalistic commodity production: a rejoinder
}

\author{
Fritz Helmedag* \\ Chemnitz University of Technology, Germany
}

Reich (2013) recapitulates my model (Helmedag 2012a) incorrectly. Above all, he mixes up exogenous with endogenous variables. Moreover, Reich's interpretation of the system's dynamics is on the one hand formally insufficient; on the other hand, matters are presented in a more complicated way than necessary.

Keywords: effective demand, employment, income shares, labour theory of value, rate of profit

JEL codes: $A 10, B 12, E 10$

In a recently published article I advanced an attempt 'to lay bare the fundamental causal relationships that determine employment and distribution in an economy based on wage labour' (Helmedag 2012a: 23). In order to see what is hidden behind the scenes, output is divided from the demand side into two classes. The first collection comprises 'necessaries' or 'basics' financed out of the wage bill. All other goods are labeled 'luxuries'. On an elementary level, this heading refers to capitalistic consumption alone since the model depicts a closed economy without a government. From a physical point of view, objects in both groups may be the same. However, identical items are categorized differently according to the income spent - that is, from either wages or profits. By means of input-output analysis, the corresponding two vertically integrated subsystems can be separated.

It proves to be a basic principle of capitalistic commodity production that the rate of profit as a pure number $(s)$ is determined in the wage-good sector where input and output are dimensionally homogenous. Let $B$ denote the quantity of the (theoretically created) wage-good produced in a certain period, $p_{B}$ its price, $v_{B}$ the labour value incorporated in a unit and $w$ the hourly real wage. The system's key variable was calculated in my original paper (here labelled H-6a) as a relation between profits and total costs in the production of wage goods:

$$
s=\frac{B p_{B}-B v_{B} w p_{B}}{B v_{B} w p_{B}}=\frac{1-v_{B} w}{v_{B} w} .
$$

Surprisingly enough, in a comment on my analysis, Reich (2013) reproduces the above expression in his equation (R-1), ${ }^{1}$ yet without simplifying it to the fraction on the right-hand side. Though Reich incidentally mentions the fact that the rate of profit is specified in the wage-good sector, he ignores the consequences for the fabric of

* Corresponding Address: Prof. Dr. Fritz Helmedag, Department of Economics, Chemnitz University of Technology, D-09107 Chemnitz, e-mail: f.helmedag@wirtschaft.tu-chemnitz.de.

1. Again, a letter in brackets refers to the corresponding paper either by Helmedag (2012a) or by Reich (2013). 
the economy. Therefore, Reich's annotations essentially boil down to a juxtaposition of my (differently written) equations where he repeatedly reads into identities arbitrarily chosen causal relations. 'Thus, without identifying the driving forces beneath the surface, the modus operandi of modern capitalism remains shrouded in mystery' (Helmedag 2012a: 24).

The 'monetary' rate of profit $s(\mathrm{H}-6 \mathrm{a})$ - which also represents a 'material' rate of surplus value (H-6b) or a 'temporal' rate of exploitation $(\mathrm{H}-6 \mathrm{c})$ - is established in the basic industry and nowhere else. In contrast, Reich asserts: 'The luxury sector is of the same structure' (Reich 2013: 275). Consequently, he distorts my equation (H-8) by tacitly substituting in equation (R-2) $s$ for the rate of profit in the luxury division $s_{X}$. But this sector is unable to fix a rate of profit without recourse to the wage-good department. As a result, a further principle of capitalism emerges: the rest of the economy has to take over the rate constituted in the basic sector. This causal hierarchy ensures that in equilibrium $\left(s=s_{X}\right)$ the prices in our two-commodity world are governed by labour embodied (H-9). This 'law of value' represents far more than 'a special case' (Reich 2013: 275).

Furthermore, Reich does not realize that the task of the profit rate consists in allocating an existent total gain - stemming in a Kaldor-Kalecki vein from the expenditures of non-workers (H-16) - to the two branches. As another principle, the part of profits accruing to the wage-good industry is equal to the 'value of labour power' $v_{B} w<1$ coinciding with real unit labour costs resp. the wage share in national income $(\mathrm{H}-13)$. Remaining returns go to the luxury division. Given the labour value of the wage-good $v_{B}$, the distribution of a certain amount of surplus therefore varies with the real wage $w$ determined in the basic sector. Obviously, both industries pursue opposing interests regarding the remuneration of workers. ${ }^{2}$ This is the reason why Reich's supposition that a higher profit rate may lead to a higher demand for luxuries (Reich 2013: 278) is unfounded: if employees do not save, total profits depend neither on workers' earnings nor on the rate of profit.

Alas, Reich takes no notice of the fundamental divergence in the capitalists' camp and invokes without discrimination 'an antagonistic relation of profits and wages' (Reich 2013: 275). Yet it is the profit rate which shapes the structure of the economy: the relation of employment in the non-basic industry $\left(L_{X}\right)$ to that in the basic sector $\left(L_{B}\right)$ as well as the corresponding real $(X)$ and nominal profits $(\Pi)$ :

$$
s=\frac{L_{X}}{L_{B}}=\frac{X_{X}}{X_{B}}=\frac{\Pi_{X}}{\Pi_{B}} .
$$

Reich suppresses the direction in which equation (H-15) must be read and surmises arbitrariness instead: 'If the composition of input or output changes, distribution has to change and vice versa' (Reich 2013: 276).

Reich sometimes transforms (mathematical) arguments into endogenous magnitudes and the other way round. For example, Reich supposes the real wage $w$ to be an unknown (Reich 2013: 275), whereas in my model it is a pre-set quantity (though nevertheless liable to undergo alterations). The same applies to the demand for luxuries (including investments) which is 'deemed completely autonomous, i.e. its volume appears as a given parameter' (Helmedag 2012a: 24). Reich omits the preceding detailed definition. Rather, the exogenous variable is presented as a constant though

2. Under certain conditions characterizing 'free competition', the rate of profits equals $100 \%$. This implies a labour power $v_{B} w$ to the tune of $50 \%$. Then, referring to a phrase coined by Marx, 'capitalistic communism' prevails (Helmedag 2012b). 
it may quite possibly change (Reich 2013: 279). According to Reich it is 'of highest importance' for my results that 'the recipients of profits have no incentive to increase their absolute level of expenditure. They are fully saturated' (Reich 2013: 280). Nothing could be further from the truth: nowhere had I considered capitalists to be in a state of bliss nor do I deny that exports or the provisions of public goods affect the production of non-basics in an economy with idle capacities. On the contrary, economic activity can (and should) be regulated by a variation of discretionary spending.

Of course, total employment encompasses more than the manpower needed to manufacture non-basic goods. In addition, the wage basket has to be supplied. But capitalism in itself does not aim to enhance workers' consumption. This is just a by-product of the system in action. Employment in the basic sector depends on the one in the luxury division and the rate of profit. With $v_{X}$ indicating the labour value of a unit of the non-basic output $X$, total employment $(L)$ amounts to:

$$
L=L_{X}+L_{B}=\left(1+\frac{1}{s}\right) v_{X} X=\frac{v_{X} X}{1-v_{B} w} .
$$

Evidently, the volume of work is governed by four parameters $v_{X}, X, v_{B}$ and $w$. Ceteris paribus, it rises with autonomous demand $X$ and the real wage $w$. However, increasing productivities - that is, decreasing labour values - entail a decline in employment. Reich resorts to a reduced version of the above equation where the right-hand side is missing (R-10). In order to examine the labour requirements, Reich (2013: 277) rewrites the penultimate expression of (H-11) in growth terms using $s^{\prime}$ as shorthand for $1 / s$ :

$$
g_{L}=g_{s^{\prime}}+g_{v_{X}}+g_{X}
$$

Reich assesses in the following numerous constellations of the growth rates. But his efforts prove futile. First, his equation (R-11) is (at least) incomplete. Correctly written, it reads:

$$
g_{L}=\frac{d L}{L}=\frac{d\left(\left(1+s^{\prime}\right) v_{X} X\right)}{\left(1+s^{\prime}\right) v_{X} X}=\frac{s^{\prime}}{1+s^{\prime}} g_{s^{\prime}}+g_{v_{X}}+g_{X} .
$$

Consequently, Reich's casuistic considerations require thorough revision. But the result will hardly be worth all that expense since, second, the rate of profit is an endogenous variable depending as mentioned above on the parameters $v_{B}$ and $w$. Again, Reich should have based his enquiry on the simplified formula on the right-hand side of equation (H-11). Then we get, for the rate of change in employment,

$$
g_{L}=\frac{d L}{L}=\frac{d\left(\frac{v_{X} X}{1-v_{B} w}\right)}{\frac{v_{X} X}{1-v_{B} w}}=\frac{v_{B} w}{1-v_{B} w}\left(g_{v_{B}}+g_{w}\right)+g_{v_{X}}+g_{X} .
$$

Equation (b) exhibits the driving forces of working time in the present setting. Process innovations are a characteristic of capitalistic development and find expression in improving labour productivities. Accordingly, the growth rates of the labour values are negative: $g_{v_{B}}<0, g_{v_{X}}<0$. Provided that the pay rises as much as the productivity gain in the basic sector $\left(-g_{v_{B}}=g_{w}\right)$, the bracket on the right-hand side of equation (b) vanishes. Remarkably, such a productivity-oriented wage policy alone does not suffice 
to stabilize employment. Only if the increase in demand for non-basics matches exactly the higher efficiency of labour expended on their production $\left(-g_{v_{X}}=g_{X}\right)$ does the level of economic activity remain unaltered $\left(g_{L}=0\right) .{ }^{3}$ The intention to create additional jobs necessitates an even stronger increment of autonomous expenditures. From this perspective I agree, after all, with Reich's last sentence to the effect that my approach can be understood as a plea for a strong public sector and social insurances.

\section{REFERENCES}

Helmedag, F. (2012a): Principles of capitalistic commodity production, in: Intervention: European Journal of Economics and Economic Policies, 9, 23-34.

Helmedag, F. (2012b): Kapitalistischer Kommunismus, in: Grötzinger, G., Reich, U.-P. (eds), Entfremdung - Ausbeutung - Revolte, Karl Marx neu verhandelt, Marburg: Metropolis, 111-126.

Helmedag, F. (2012c): Effektive Nachfrage, Löhne und Beschäftigung, in: Kromphardt, J. (ed.), Keynes' General Theory nach 75 Jahren, Marburg: Metropolis, 93-106.

Reich, J. (2013): Principles of capitalistic commodity production reconsidered, in: European Journal of Economics and Economic Policies: Intervention, 10(3), 274-281.

3. This result corroborates a similar finding in Helmedag (2012c). 